Article

\title{
Hydrodynamic Structure with Scour Hole Downstream of Bed Sills
}

\author{
Mouldi Ben Meftah* ${ }^{\mathbb{D}}$, Francesca De Serio $\mathbb{D}$, Diana De Padova $\mathbb{D}$ and Michele Mossa \\ Department of Civil, Environmental, Land, Building Engineering and Chemistry, Polytechnic University of Bari, \\ Via E. Orabona 4, 70125 Bari, Italy; francesca.deserio@poliba.it (F.D.S.); diana.depadova@poliba.it (D.D.P.); \\ michele.mossa@poliba.it (M.M.) \\ * Correspondence: mouldi.benmeftah@poliba.it; Tel.: +39-080-5963-508
}

Received: 2 December 2019; Accepted: 6 January 2020; Published: 9 January 2020

\begin{abstract}
Experimental turbulence measurements of scour hole downstream of bed sills in alluvial channels with non-cohesive sediments are investigated. Using an Acoustic Doppler Velocimeter (ADV), the flow velocity-field within the equilibrium scour hole was comprehensively measured. In this study, we especially focus on the flow hydrodynamic structure in the scour hole at equilibrium. In addition to the flow velocity distribution in the equilibrium scour hole, the turbulence intensities, the Reynolds shear stresses, the turbulent kinetic energy, and the turbulent length scales are analyzed. Since the prediction of equilibrium scour features is always very uncertain, in this study and based on laboratory turbulence measurements, we apply the phenomenological theory of turbulence to predict the maximum equilibrium scour depth. With this approach, we obtain a new scaling of the maximum scour depth at equilibrium, which is validated using experimental data, satisfying the validity of a spectral exponent equal to $-5 / 3$. The proposed scaling shows a quite reasonable accuracy in predicting the equilibrium scour depth in different hydraulic structures.
\end{abstract}

Keywords: scour; velocity field; turbulence; equilibrium scour depth; new scaling of scour depth

\section{Introduction}

Prediction of maximum scour depth downstream of hydraulic structure i.e., bridge piers and abutments, sills, sluice gates, spillways, weirs, offshore platforms, wind turbines, etc., is of primary concern for a wide range of engineering and environmental applications. This topic has drawn attention and interest from many researchers for decades [1-14]. Despite these numerous studies, prediction of equilibrium-scour hole characteristics always remains challenging because of the complexity of the phenomenon and its dynamic sensitivity to structure and sediment properties. Most of these studies [3-9,12-14] proposed different empirical formulae based on experimental/field measurements, to predict the maximum eroded depth, its maximum length, and other properties. Ben Meftah and Mossa [3], Tregnaghi et al. [14], and Lu et al. [15] observed that, based on laboratory measurements of steady/unsteady flows, the scour downstream of a grade control structure evolves into three distinct phases, including an initial phase, a developing phase, and an equilibrium phase. Tregnaghi et al. [14] argued that the scour process usually reaches its equilibrium condition rapidly in live-bed conditions and rather slowly in clear-water conditions. Lu et al. [15] indicated that the scour hole in non-cohesive sediments is influenced by both the channel characteristics and the sediment properties, especially the channel bed slope, the densimetric Froude number, the tailwater depth, and the sediment median size.

The enormous amount of studies conducted on this issue asserts that the scour hole profiles are similar in shape, giving rise to a typical profile with appropriate scaling of the horizontal and vertical coordinates. However, in spite of the great effort made by researchers, many different formulae were derived to predict the scour profile at equilibrium. This large number of different empirical 
formulae, sometimes composed of complicated parameters, makes them less operational in practice than expected. Moreover, most of these formulae are affected by large uncertainties and suffer some limitations. According to Manes and Brocchini [16], the approaches based on dimensional analysis suffer from two main shortcomings: One due to the experimental laboratory scale issues, hiding the real shape of functional relations between non-dimensional groups at field scales, and the other one is related to the fact that the empirical approach does not provide a theoretical framework to interpret the experimental data and to understand the physics underlying such functional relations.

Recent studies [16-19] proposed very important and innovative approaches to predict localized turbulent flow scours, applying the phenomenological theory of turbulence (PTT). This approach hypothesizes that the scour process is controlled by the momentum transport generated by eddies belonging to the dissipation and production spectrum ranges. By scaling the eddy-characteristic-lengths of these spectrum-ranges with the equilibrium-scour dimensions and the characteristic-sediment-length, researchers tried to derive general predictive formulae, by merging the PTT-theoretical aspects with empirical observations, for the equilibrium maximum-scour depth at some hydraulic structure.

The main aim of this study is to contribute to this novel kind of approach, being the prediction of the scour features based on experiments and theory still challenging due to the complexity of the phenomenon. Therefore, in the present study, we first experimentally focus on the flow turbulence measurements in a scour hole developed downstream of a grade control structure in sand-bed channels, providing an integrated hydrodynamic picture of the scouring process. Successively, we propose a new scaling of the maximum scour depth at equilibrium and validate it using the experimental data of this study and some data collected from previous studies. Specifically, the proposed scaling approach is easy to use, depending in particular on a densimetric Froude number and on a relative roughness. Nevertheless, its application shows a quite reasonable accuracy in predicting the equilibrium scour depth in different hydraulic structures. Therefore, our findings would contribute to improve the understanding of the scouring mechanisms by applying the phenomenological theory of turbulence.

\section{Experimental Set-Up}

The experiments on the scour processes were carried out in a rectangular flume of closed-circuit flow at the Hydraulic Laboratory of the Mediterranean Agronomic Institute of Bari (Italy). The flume has glass sidewalls and a Plexiglass floor, allowing a good side view of the flow. It is $7.72 \mathrm{~m}$ long, $0.30 \mathrm{~m}$ wide, and $0.40 \mathrm{~m}$ deep. A pump of maximum discharge of $24 \mathrm{l} / \mathrm{s}$ was used to deliver water from the laboratory sump to an upstream tank equipped with a baffle and lateral weir, maintaining a constant head upstream of a movable slide-gate constructed at the inlet of the flume. The slide-gate regulates channel flow-discharge. To create a smooth flow transition from the upstream reservoir to the flume, a wooden ramp was installed at the inlet of the flume; it is $1.55 \mathrm{~m}$ long, $0.15 \mathrm{~m}$ thick and of same channel width (Figure 1). At the outlet of the flume, water is intercepted by a stilling tank, equipped with three vertical grids to stabilize water, and a triangular weir (V-notch sharp crested weir) to measure discharge with relative uncertainty of $\pm 8 \%$. At the downstream end of the flume, a movable gate made of Plexiglass and hinged at the channel bottom is used to regulate the flow depth.

In order to simulate grade control structures protecting riverbeds against erosion, in this study we have used a series of sills consisting of PVC plates $0.30 \mathrm{~m}$ wide and $0.01 \mathrm{~m}$ thick. The sills were installed on an experimental area extended $6 \mathrm{~m}$ along the channel, downstream of the wooden ramp. The sill height decreases progressively going downstream from the wooden ramp, respecting a determined initial slope $S_{0}$ of 0.0086 . Different configurations were investigated, the difference between them being the distance, $L$, between sills. More details on the sills distribution are reported in Ben Meftah and Mossa [3].

The flume bottom downstream of the wooden ramp and between the sills is covered with an erodible bed material layer, consisting of almost uniform sand particles with a mean average size, $d_{50}$, of $1.8 \mathrm{~mm}$ and density of $2650 \mathrm{~kg} / \mathrm{m}^{3}$ (see Ben Meftah and Mossa [3] for more information). Along the 
experimental area, the sand layer was leveled respecting the maximum sill heights and that of the upstream wooden ramp, forming the original bed of the channel with a slope $S_{0}$ (Figure 1).

\section{Front view}

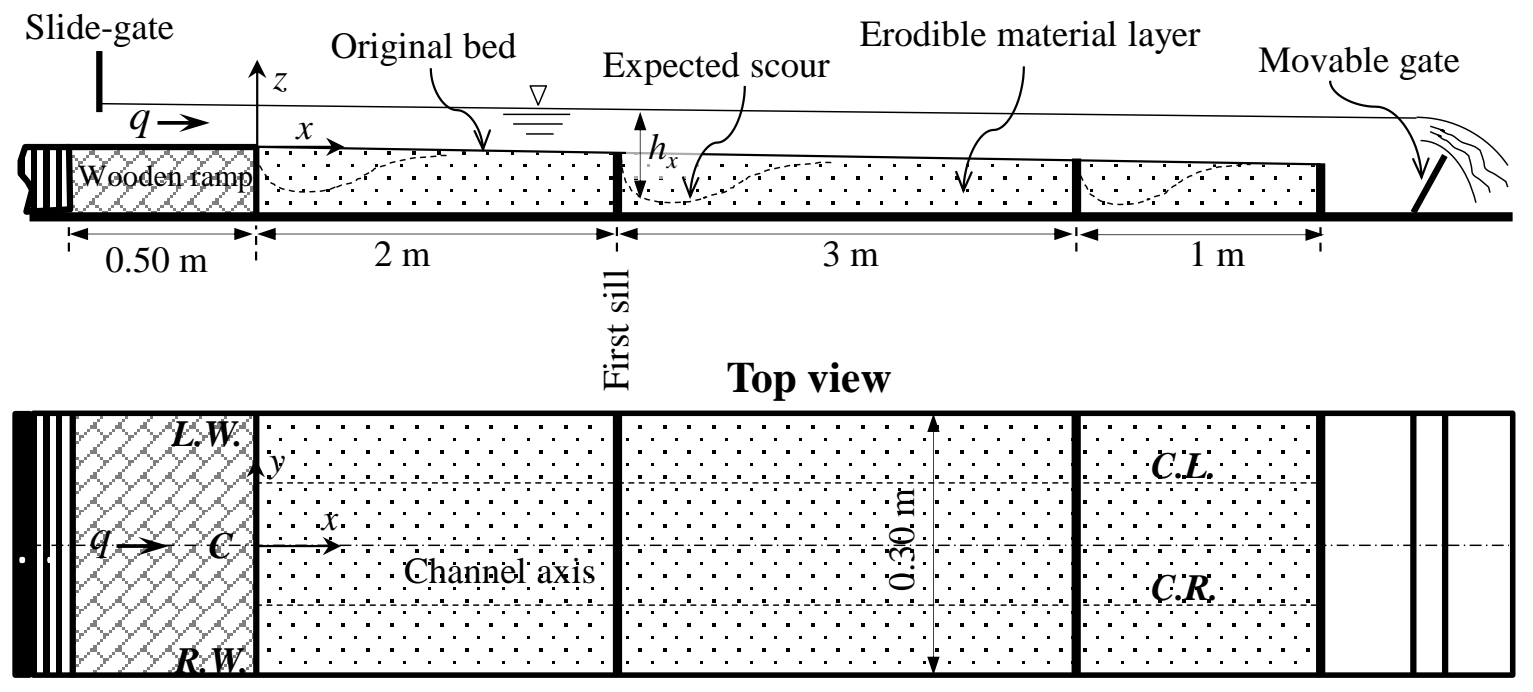

Figure 1. General sketch of the laboratory flume with the initial condition and expected scour hole (dashed profile) downstream of bed sills. $h_{x}=$ flow depth in the expected equilibrium scour at a downstream position $x, \mathrm{~L} . \mathrm{W}$. = left wall side of channel, R.W. = right wall side, $\mathrm{C}=$ centerline (channel axis), C.L. = centerline of left half of channel, and C.R. = centerline of right half, $(x, y, z)=$ longitudinal, transversal, and vertical directions, respectively.

The data collected during each test included discharge, water surface elevation, flow depth, temporally eroded bed profile, equilibrium bed profile, and scour dimensions (depth, length, position of maximum depth). The profiles of the equilibrium eroded bed along the channel centerline, near the channel sidewalls, and at an intermediate distance between the channel centerline and both sidewalls (Figure 1) were measured, as the vertical distance between the initial bed elevation and the bed at equilibrium, by means of a point gauge of $\pm 0.1 \mathrm{~mm}$ accuracy. The water level profile along the channel centerline was measured using an electrical hydrometer with an accuracy of $\pm 0.1 \mathrm{~mm}$.

In addition to the measurements of the scour geometric characteristics, the flow velocity-fields were also carried out in the scour hole at equilibrium condition. The velocity data were collected using a 3D Acoustic Doppler Velocimeter (ADV) system, developed by Nortek, with a sampling rate of $25 \mathrm{~Hz}$ at a time window of $70 \mathrm{~s}$. The sampling volume of the ADV was located $5 \mathrm{~cm}$ below the transmitter probe. The ADV was used with a velocity range equal to $\pm 0.30 \mathrm{~m} / \mathrm{s}$, a measured velocity accuracy of $\pm 1 \%$, and a sampling volume of less than $0.25 \mathrm{~cm}^{3}$. For high-resolution measurements, the manufacturer recommends a $15 \mathrm{db}$ signal-to-noise ratio (SNR) and a correlation coefficient larger than $70 \%$. The acquired data were filtered based on the Tukey's method and bad samples (SNR $<15 \mathrm{db}$ and correlation coefficient $<70 \%$ ) were also removed. Additional details concerning the ADV-system operations can be found in [20-27]. Flow velocity measurements through the scour hole were carried out for different configurations in both the longitudinal plane of symmetry and in some transversal planes.

The initial experimental conditions and the geometric characteristics of scours, related to this study, are illustrated in Table 1 , where $h_{c}$ is the flow depth over the crest of the sill downstream of which the scour hole is measured, $U_{c}$ is the flow velocity over the sill (mean velocity in correspondence of $h_{c}$ ), $z_{S}$ is the maximum equilibrium scour depth from the original bed profile, $h_{S}$ is the flow depth at the position of maximum equilibrium scour depth, $\lambda_{c}=d_{50} / h_{c}$ is a relative roughness, $F_{d c}=U_{c} /\left(\Delta g d_{50}\right)^{0.5}$ is the densimetric Froude number for the approach flow over the sill, $\Delta=\left[\left(\rho_{s}-\rho_{w}\right) / \rho_{w}\right]$ is the submerged relative density of sediment particles, $\rho_{w}$ is the water density, $\rho_{s}$ is the sediment density, $g$ is the 
gravitational acceleration, $R e_{c}=U c h c / v$ is the Reynolds number for the approach flow over the sill, $R e_{g}=U_{c} d_{50} / v$ is the grain Reynolds numbers, and $v$ is the water kinematic viscosity. For the sake of brevity, in this study we focus in detail on data of run T21 (Table 1) for the analysis of the turbulent parameters, while we adopt all runs (T04-T22) in the scaling procedure.

Table 1. Initial experimental conditions and parameters of the investigated runs.

\begin{tabular}{|c|c|c|c|c|c|c|c|c|c|}
\hline Runs & $\begin{array}{c}L \\
(\mathrm{~m})\end{array}$ & $\begin{array}{c}h_{c} \\
(\mathrm{~m})\end{array}$ & $\begin{array}{c}U_{c} \\
(\mathrm{~m} / \mathrm{s})\end{array}$ & $\begin{array}{c}z_{s} \\
(\mathrm{~m})\end{array}$ & $\begin{array}{c}h_{s} \\
(\mathrm{~m})\end{array}$ & $\begin{array}{c}F_{d c} \\
(-)\end{array}$ & $\begin{array}{l}\lambda \\
(-)\end{array}$ & $\begin{array}{c}R e_{c} \\
(-)\end{array}$ & $\begin{array}{c}R e_{g} \\
(-)\end{array}$ \\
\hline T04 & 1 & 0.035 & 0.593 & 0.039 & 0.10 & 3.474 & 0.051 & 18,159 & 934 \\
\hline T05 & 1 & 0.048 & 0.689 & 0.088 & 0.15 & 4.035 & 0.038 & 28,517 & 1069 \\
\hline T06 & 1 & 0.029 & 0.522 & 0.028 & 0.08 & 3.060 & 0.062 & 12,497 & 776 \\
\hline T07 & 1 & 0.054 & 0.726 & 0.105 & 0.18 & 4.255 & 0.033 & 32,354 & 1078 \\
\hline T08 & 1 & 0.042 & 0.647 & 0.064 & 0.13 & 3.790 & 0.043 & 23,774 & 1019 \\
\hline T09 & 2 & 0.036 & 0.585 & 0.053 & 0.09 & 3.425 & 0.050 & 18,942 & 947 \\
\hline $\mathrm{T} 10$ & 2 & 0.042 & 0.634 & 0.057 & 0.12 & 3.717 & 0.043 & 25,981 & 1113 \\
\hline T11 & 2 & 0.048 & 0.688 & 0.070 & 0.13 & 4.033 & 0.038 & 32,217 & 1208 \\
\hline $\mathrm{T} 12$ & 2 & 0.054 & 0.736 & 0.081 & 0.15 & 4.312 & 0.033 & 39,743 & 1325 \\
\hline $\mathrm{T} 13$ & 2 & 0.060 & 0.762 & 0.090 & 0.17 & 4.466 & 0.030 & 46,880 & 1406 \\
\hline T14 & 4 & 0.034 & 0.576 & 0.076 & 0.09 & 3.374 & 0.053 & 20,563 & 1089 \\
\hline T15 & 4 & 0.042 & 0.647 & 0.090 & 0.12 & 3.790 & 0.043 & 29,208 & 1252 \\
\hline T16 & 4 & 0.048 & 0.691 & 0.112 & 0.14 & 4.048 & 0.038 & 37,309 & 1399 \\
\hline $\mathrm{T} 17$ & 4 & 0.030 & 0.533 & 0.065 & 0.08 & 3.125 & 0.060 & 18,000 & 1080 \\
\hline T18 & 3 & 0.029 & 0.531 & 0.050 & 0.07 & 3.113 & 0.062 & 17,721 & 1100 \\
\hline T19 & 3 & 0.036 & 0.586 & 0.061 & 0.10 & 3.433 & 0.050 & 24,784 & 1239 \\
\hline T20 & 3 & 0.042 & 0.653 & 0.071 & 0.12 & 3.827 & 0.043 & 32,236 & 1382 \\
\hline $\mathrm{T} 21$ & 3 & 0.048 & 0.686 & 0.084 & 0.14 & 4.019 & 0.038 & 38,688 & 1451 \\
\hline $\mathrm{T} 22$ & 3 & 0.052 & 0.762 & 0.094 & 0.17 & 4.463 & 0.035 & 46,543 & 1611 \\
\hline
\end{tabular}

\section{Results and Discussion}

\subsection{Velocity Fields}

Since turbulence is the most important mechanism of sediment entrainment, causing a significant increase in the shear stress around the base of a hydraulic structure, a large set of measurements of the flow velocity field in the scour holes was carried out. Figure 2, as an example, shows a vector map of the flow velocity, $V_{x z}$, in the scour hole downstream of the first bed sill, located $2 \mathrm{~m}$ downstream of the wooden ramp (Figure 1). In Figure 2 the $(x, z)$-coordinates take origins at the first sill position and the channel bottom, respectively. The $V_{x z}$-velocity is the resultant of the streamwise $U$ and vertical $W$ time-averaged velocity components. The three profiles of the initial bed (solid line), the free-surface flow (triangle down), and the bed at equilibrium condition (bullet) are also reported in Figure 2. The random point cloud in Figure 2 represents the remaining amount of sediment between sills at scour-equilibrium. All the data illustrated in Figure 2 were obtained in the plane of flow-symmetry $(y=0)$.

Figure 2 clearly shows the flow velocity behavior through the scour hole. Three flow velocity distribution regions can be recognized in Figure 2: (i) A first region, 1, where a sort of a free entering jet flows, originated by the flow condition over the sill-crest; (ii) a second region, 2, characterized by vortex formations (eddies) due to the jet diffusion, located near the bottom of the scour hole and extended along the upstream scour-side; and (iii) a third region, 3, seeming less turbulent and taking place downstream, outside the vortex region. Between the regions 1 and 2, a sort of a hydraulic jump may occur, depending on the hydraulic conditions. The absence of velocity measurements in the upper flow region is due to the limitation of the ADV-downlooking probe, being the uppermost $7 \mathrm{~cm}$ of the flow could not be sampled. However, in the jet-like region 1, the acquired ADV-signal was very noisy, which could be due to the strong jet-flow agitation interacting with the hydraulic jump. 


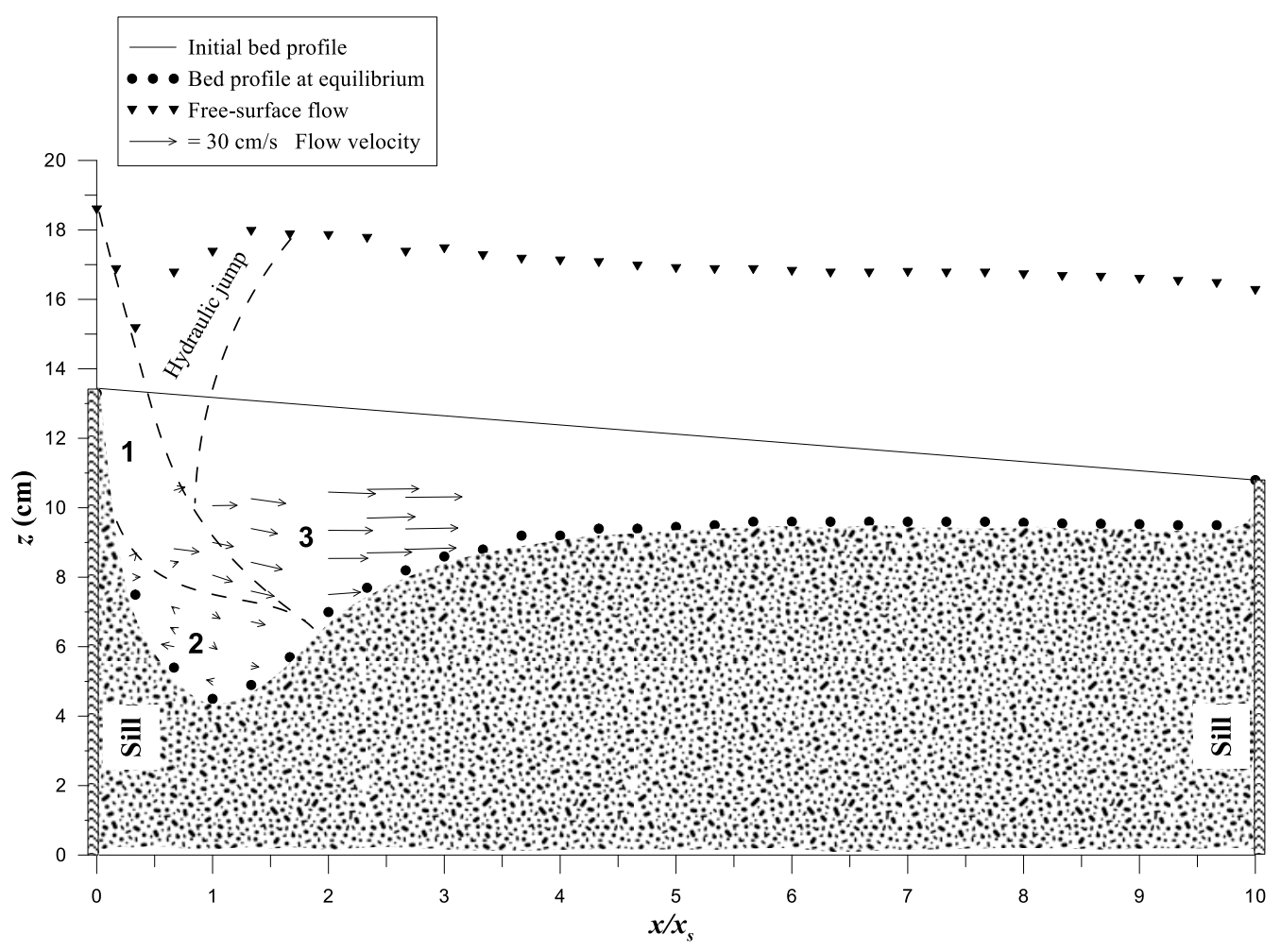

Figure 2. Vector map of the flow velocity, $V_{x z}$, in the scour hole at the plane of flow-symmetry $(y=0)$. The dashed line qualitatively indicates the separation between regions 1, 2, and 3 .

The jet-like flow (region 1) plays a crucial role in the different phases of the scour development. This is due to its high velocity, which leads to an increase of the jet potential erosive action on the bed channel. As the jet size increases over time, the jet begins to gradually lose its erosive potential. The state of equilibrium occurs when the path of the impinging jet becomes sufficiently long and its diffused velocity is reduced to values lower than the minimum value required for sediment movement [28].

In the region 2 (Figure 2), a significant reduction of the flow velocity occurs. Furthermore, the flow distribution shows two portions: A portion of negative velocity starting at the position of maximum scour depth and extending towards the upward bed sill, forming a sort of clockwise local vortex, and another portion of positive velocity that shifts the flow downstream, from the position of the maximum scour depth. Similar behaviors have been observed by Ghodsian et al. [29]. The authors named as "weak flow" the portion of negative velocity and "strong flow" the portion of positive velocity. They also observed that the lowest region of the scour hole is mainly covered by the sediment of size $d_{90}$, grain size for which $90 \%$ of sampled particles are finer.

In the region 3 (Figure 2), the flow velocity considerably increases, compared to region 2. This increase is gradual in the downstream direction. Moreover, the velocity vectors tend to be more horizontal and of almost comparable values. The flow redistribution in region 3 indicates a sort of smooth transition flow from scour hole to the downstream tailwater flow. This smooth transitional flow result in less flow turbulence, which is the subject of the next section.

\subsection{Turbulence Intensity Associated with Scour Hole}

To get further information on the scouring process, in Figure 3 we plot the streamwise turbulence intensity, $U^{\prime}$, as a function of the normalized vertical coordinate $Z / z_{s}$. Herein, $U^{\prime}$ was defined as the ratio of the standard deviation of the streamwise flow-velocity component fluctuations to the average velocity, $U_{c}$, measured over the sill-crest, $Z$ is the vertical position from the original bed profile (solid line in Figure 2) at a given downstream position $x$. The vertical $U^{\prime}$-profiles correspond to different downstream positions $x / x_{s}=0.33,0.67,1.00,1.33,2.00,2.33$, and 2.67, where $x_{s}$ is the $x$-position from 
the grade-control structure (sill) at which the scour attains its maximum depth. Note that, due to the flow symmetry, the spanwise velocity, $V$, is theoretically expected to be null and therefore it has not any physical significance in this plane.

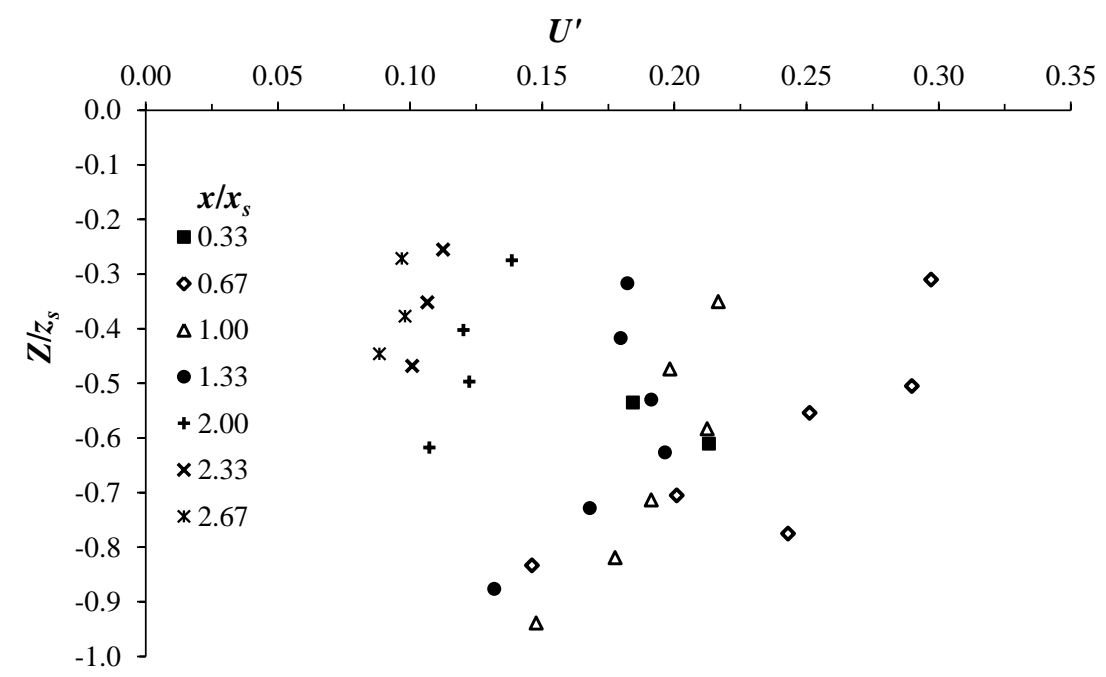

Figure 3. Vertical profiles of streamwise turbulence intensity, $U^{\prime}$, at different downstream positions $x / x_{s}$ along the plane of flow symmetry $(y=0)$.

Figure 3 shows that the maximum turbulence intensities take place at $x / x_{s} \leq 1.33$, at the regions 1 , 2 and the upstream side of region 3 . At these regions, which practically occupy the whole part of the main scour hole, the values of turbulence intensities range between a minimum of 0.13 and a maximum of 0.3. At $x / x_{s}=0.67, U^{\prime}$ experiences the maximum measured values at $Z / z_{s} \geq-0.7$. This position is located within the region 1 , where the jet flow penetrates into the scour pool, generating high levels of turbulence. Figure 3 mainly indicates a tendency of $U^{\prime}$ to reduce as going down towards the scour bed. In region 2 , at $Z / z_{s}<-0.7, U^{\prime}$ reduces by almost $50 \%$ as compared to region 1 . The significant reduction in turbulence intensity in region 2 is related to the sharp decrease in flow velocity in this region, as shown in Figure 2. At the exit from the scour hole, at $x / x_{s}>1.33$ in region $3, U^{\prime}$ shows the smallest values, as expected based on the flow velocity distribution (Section 3.1). At this region, $U^{\prime}$ decreases almost twice compared to region 1 and by $60 \%$ compared to region 3 .

In Figure 4 we plot the vertical turbulence intensity, $W^{\prime}$, profiles at the same downstream positions $x / x_{s}=0.33,0.67,1.00,1.33,2.00,2.33$, and 2.67. Herein, $W^{\prime}$ is defined as the ratio of the standard deviation of the vertical flow-velocity component fluctuations to $U_{c}$. Figure 4 clearly shows a substantial reduction in $W^{\prime}$ as compared to $U^{\prime}$. For all the profiles, $W^{\prime}$ ranges between a minimum of 0.03 and a maximum of 0.17 against 0.13 and 0.30 , respectively, observed for $U^{\prime}$. Furthermore, at the different downstream positions $x / x_{s}, W^{\prime}$ decreases with decreasing $Z / z_{\mathcal{S}}$ (i.e., going down to the equilibrium-scour bed). This decrease is continuous and with a significant reduction rate as compared to $U^{\prime}$. This may be explained by the considerable reduction of the vertical velocity flow going towards the equilibrium bed profile, which effectively reduces the vertical flow-force that could lift the sediments from the bottom. Similar to $U^{\prime}, W^{\prime}$ experiences maximum values in region 1 and at the upstream side of region 3. In region 2 however, $W^{\prime}$ exhibits the smallest values, comparable to those that occurred in region 3. 


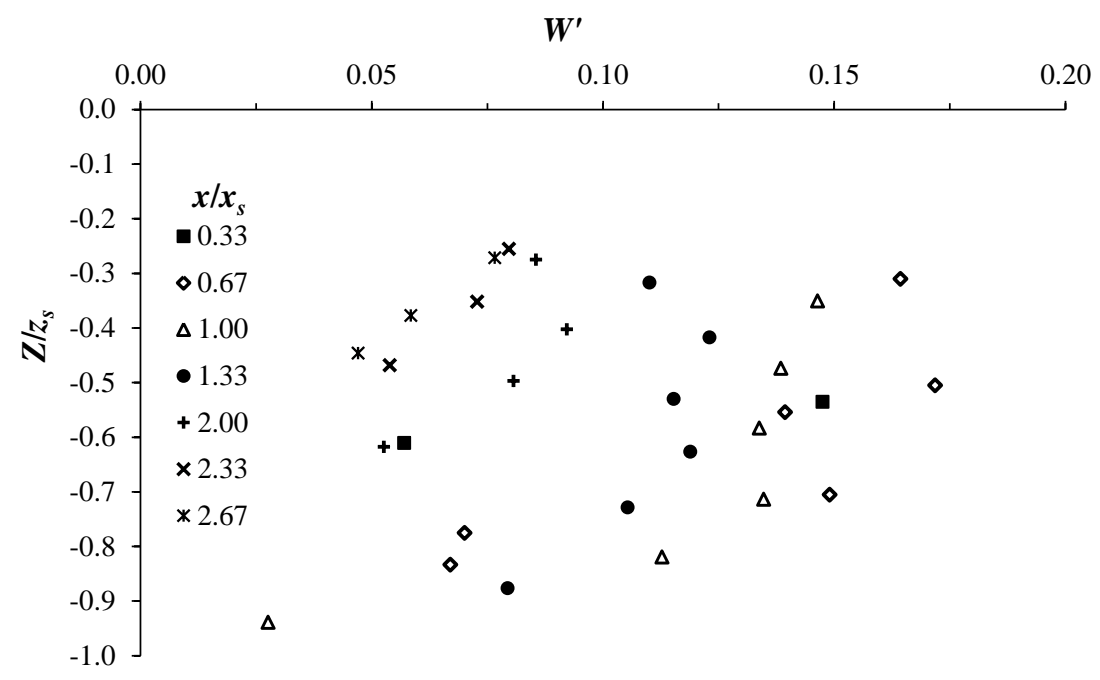

Figure 4. Profiles of vertical turbulence intensity, $W^{\prime}$, at different downstream positions $x / x_{s}$ along the plane of flow symmetry $(y=0)$.

Figure 5 illustrates the vertical profiles of the normalized Reynolds shear stresses in the scour hole. The profiles were taken at the downstream positions $x / x_{s}=0.33,0.67,1.00,1.33,2.00,2.33$, and 2.67. In Figure $5, U^{\prime} W^{\prime}=-\left\langle u^{\prime} w^{\prime}>/ U_{c}{ }^{2}\right.$, where $\left\langle u^{\prime} w^{\prime}>\right.$ is the time-averaged stress over the length of the time series and $\left(u^{\prime}, w^{\prime}\right)$ are the velocity fluctuations of the streamwise and vertical component, respectively. The values of $U^{\prime} W^{\prime}$ clearly have a heterogeneous distribution at the different downstream positions $x / x_{s}$. This heterogeneity vertically decreases downward (towards the scour bed). Furthermore, Figure 5 shows that the heterogeneity of the Reynolds stresses is spatially variable in the scour hole. At $x / x_{s}=0.67, U^{\prime} W^{\prime}$ varies from a maximum value $\mathrm{O}\left(4 \times 10^{-2}\right)$ to a value $\mathrm{O}\left(10^{-3}\right)$. Both the magnitude and the variation range of $U^{\prime} W^{\prime}$ gradually decrease with increasing $x / x_{s}$. For $x / x_{s}>1.33$, there is a sharp decrease of the Reynolds stress magnitude and the values of $U^{\prime} W^{\prime}$ tend to an homogeneous distribution, from a maximum predictable averaged value $\mathrm{O}\left(4 \times 10^{-3}\right)$ to a value $\mathrm{O}\left(10^{-3}\right)$. Figure 5 also shows that $U^{\prime} W^{\prime}$ exhibits the largest values in region 1 (see Figure 2), it decreases slightly in the upstream side of region 3 , and it is significantly reduced in region 2. At the edge of the downstream scour-side, $x / x_{s}>1.33, U^{\prime} W^{\prime}$ shows the lowest values.

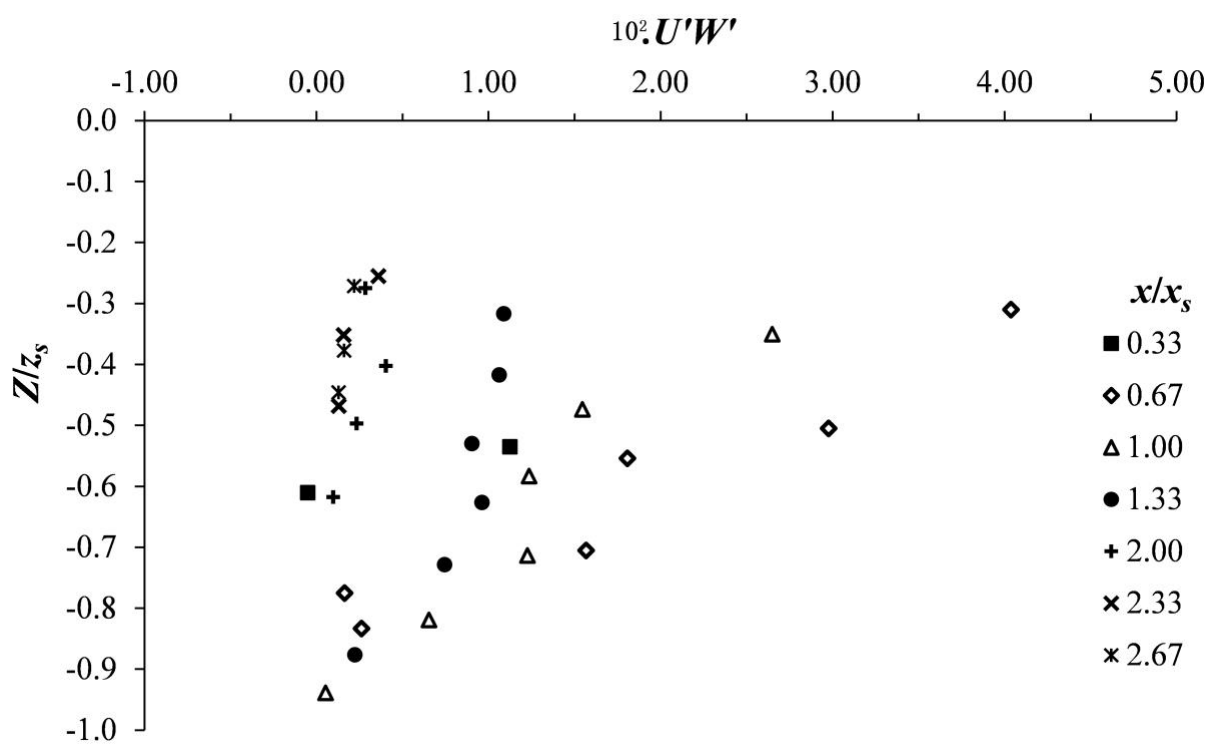

Figure 5. Vertical profiles of normalized Reynolds shear stress, $U^{\prime} W^{\prime}$, in scour hole and at different downstream positions $x / x_{s}$ along the plane of flow symmetry $(y=0)$. 
Figure 5 also indicates that $U^{\prime} W^{\prime}$ always has positive values in the scour hole, along the plane of flow symmetry $(y=0)$. This reflects a clear idea upon the frictional drag distribution and the vertical effective momentum transfer associated with the scour hole structure in the plane of flow symmetry. In the scour hole, the Reynolds shear stress is developed due to the formation of eddies of many different length scales. In the immediate vicinity of the sediment scour bed, localized turbulent eddies play an important role in removing a sediment particle from its stabilized position. According to Ali and Dey [30], at the flow-bed interface, the eddies of greater size than the sediment diameter, $d_{50}$ as an example, weakly contribute to the vertical velocity component. By contrast, the eddies of smaller size than the sediment diameter perfectly fit in the space between the particles, providing an effective contribution to the vertical velocity component and therefore a substantial transfer of the vertical momentum may occur. The increase of the vertical lift force generated by small eddies (with smaller size than the sediment diameter) and the important horizontal component of momentum transmitted by large eddies (with greater size than the sediment diameter) at the sediment bed, play a crucial role in putting the sediment particles in suspension. Applying the phenomenological theory of turbulence and a dimensional analysis, Ali and Dey [30] found a scale of the Reynold shear stress at the bed for the incipient motion of sediment particles.

$$
-\left.\rho_{w}\left\langle u^{\prime} w^{\prime}\right\rangle\right|_{b} \sim \rho_{w} U_{b}^{2} \lambda^{-\frac{(1+\sigma)}{2}}
$$

where the subscript $b$ indicates the flow-bed interface position, $U_{b}$ is the threshold velocity, defined as the near-bed velocity that is marginally sufficient to initiate the particle motion at the bed surface, $\lambda\left(=d_{50} / h_{x}\right)$ is a relative roughness, $h_{x}$ is defined in Figure $1, \sigma$ is the spectral exponent of the turbulent energy spectrum. By equating the Reynolds shear stress, obtained near the bed surface, and the bed shear stress $\tau_{b}$, we can obtain the threshold velocity $U_{b}$. $\tau_{b}$ can be related to the gravitational shear stress $\tau_{g}$ as $\tau_{b} \sim \tau_{g}=\left(\rho_{s}-\rho_{w}\right) g d_{50} \theta_{b}$, where $\theta_{b}$ is the threshold Shields parameter. $\theta_{b}$ is a function of a particle parameter $D=\left[\left(g \Delta d_{50}\right) / v^{2}\right]^{1 / 3}$. Combining the different parameters together, one obtains a scaling expression of the threshold densimetric Froude number, $F_{d b}$ :

$$
\begin{aligned}
& \rho_{w} U_{b}{ }^{2} \lambda^{-\frac{(1+\sigma)}{2}} \sim\left(\rho_{s}-\rho_{w}\right) g d_{50} f(D) \\
& F_{d b}=\frac{U_{b}}{\sqrt{\Delta g d_{50}}} \sim \lambda^{\frac{(1+\sigma)}{4}} f^{\frac{1}{2}}(D)
\end{aligned}
$$

It is worth mentioning that for a hydraulically rough flow regime the function $f(D)$ tends to a constant value.

Figure 6 depicts the vertical profiles of the time-averaged turbulent kinetic energy, $K$, normalized by $U_{c}{ }^{2}$, at different downstream positions $x / D$ from the bed sill. In the plane of flow symmetry $(\mathrm{y}=0), k=\left(\left\langle\mathrm{u}^{\prime 2}\right\rangle+\left\langle\mathrm{w}^{\prime 2}\right\rangle\right) / 2$, where the angle brackets indicate the average over the length of the time series. In the energy inertial subrange, the energy cascade yields the ' $\sigma=-5 / 3^{\prime}$ spectral law. Since the energy equilibrium in this energy subrange is maintained by the balance between the production and dissipation rate of the turbulent kinetic energy, the energy spectrum function is scaled as $E(\kappa) \sim \varepsilon^{2 / 3} \kappa^{-5 / 3}$, where $\varepsilon$ is the turbulent kinetic energy dissipation rate and $\kappa$ is the wavenumber. In this case, the turbulent kinetic energy can be scaled as $K \sim \int \varepsilon^{2 / 3} \kappa^{-5 / 3} \mathrm{~d} \kappa$. Figure 6 clearly highlights a spatial variation of $K$ within the scour flow-field. In Figure 6, all the vertical profiles, except that at $x / x_{s}=1.33$, show a decrease of $K$ as going down towards the scour bed, but with different reduction rates that depend on the downstream positions $x / x_{s}$. At $x / x_{s}=0.67, K$ experiences both the maximum values and the maximum reduction rate. This implies that the jet-like region, indicated by region 1 in Figure 2, is a location of maximum turbulent energy production. At $x / x_{s}=1.33, K$ shows an increase with increasing depth, it attains a maximum value $\mathrm{O}\left(3 \times 10^{-2}\right)$ at $Z / z_{s}=-0.6$ and then begins to decrease going down to the bed-flow interface. This fact can be explained by the transition effect between regions 1 and 3 (see Figure 2), where the jet-like diffusion is accompanied by high levels of flow-turbulence intensities and large kinetic energy production, as also observed in a previous study by Ben Meftah and Mossa [20]. 
At $x / x_{s}>1.33, k$ undergoes a sharp decrease, showing values $\mathrm{O}\left(10^{-2}\right)$, it also shows a very gradual reduction going downwards. At equilibrium scour condition, $k$ shows very small values, ranging between 0.005 and 0.013 , near the bed-flow interface for the different downstream positions $x / x_{s}$. In the scour hole, at equilibrium condition, the stability of the sediment particles is due to the significant decrease of turbulent energy production at the bed-flow interface.

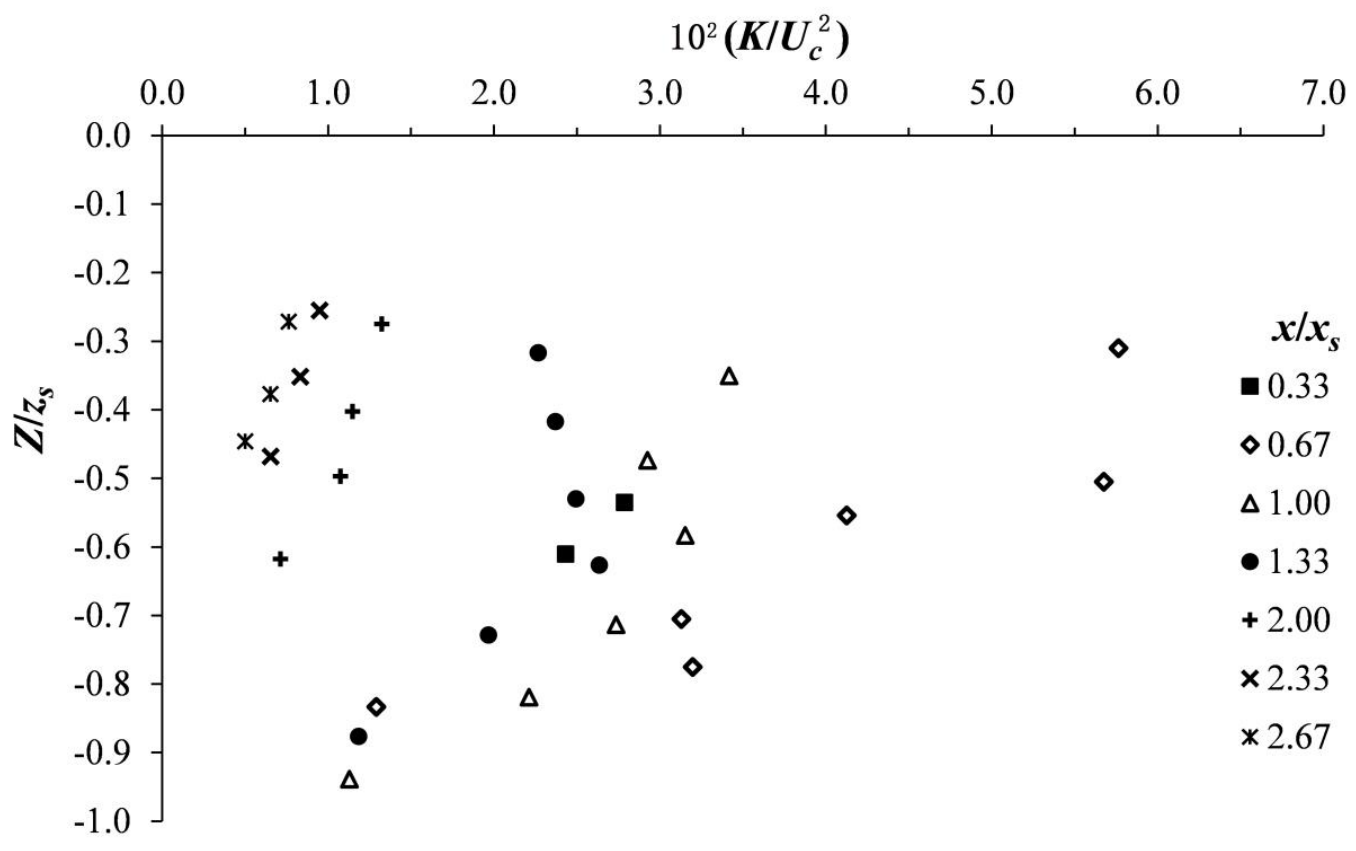

Figure 6. Vertical profiles of normalized turbulent kinetic energy, $k / U_{c}{ }^{2}$, in scour hole and at different downstream positions $x / x_{s}$ along the plane of flow symmetry $(y=0)$.

\subsection{Turbulent Length Scales}

Determination of the eddies scales in a turbulent flow is of crucial importance for experimental and numerical investigations, defining suitable domain-dimensions (area or volume) for computation [20]. Since the condition of incipient movement of the sediment particles is significantly influenced by the size of turbulent eddies, in this section, we try to experimentally determine the characteristic eddy length scales of the turbulent flow in the scour hole at equilibrium condition. The integral length scale $L_{i}\left(=L_{x}, L_{z}\right)$ is simply calculated as the product of the integral time scale $T_{i}$ and the local time-averaged velocity $U_{i}(=U, W)$, where $T_{i}\left(=T_{x}, T_{z}\right)$ is computed integrating the autocorrelation of the measured instantaneous flow velocity $u_{i}(t)[=u(t), w(t)]$. The autocorrelation of the measured instantaneous flow velocity was determined after a spectral analysis of the flow velocity fluctuation at the different measurement points.

Figures 7 and 8 depict the vertical profiles of the integral length scales $L_{x}$ and $L_{z}$, respectively, normalized by the mean average diameter of sediments, $d_{50}$, at different downstream positions $x / x_{s}$. The processed data and the downstream positions $x / x_{s}$ are the same as those covered in the previous sections. Herein, $L_{x}$ is the integral length scale in the $x$-direction and $L_{z}$ in the $z$-direction, calculated by means of the variables $\left(U, T_{x}\right)$ and $\left(W, T_{z}\right)$, respectively.

Contrary to what observed in Figures 3-6 for the flow turbulence properties in the scour hole, Figure 7 shows that larger values of $L_{x}$ occur almost at the location of lower turbulence levels. At $x / x_{s}=0.33$ and 0.64 , i.e., the positions of the jet-like flow and jet diffusion in regions 1 and 2 (Figure 2), $L_{x}$ has a size of the order of $1 \div 5 d_{50}$. At $x / x_{s}=1, L_{x}$ is considerably increased, compared to the values at the upstream positions $x / x_{s}=0.33$ and 0.64 . It vertically decreases, going down towards the scour bed, from value $\mathrm{O}\left(10 d_{50}\right)$ to value $\mathrm{O}\left(d_{50}\right)$ near the sediment bed. At $x / x_{s}=1.33, L_{x}$ shows a maximum value $\mathrm{O}\left(27 d_{50}\right)$ and it monotonically decreases with increasing depth, reaching a value $\mathrm{O}\left(7 d_{50}\right)$ close to 
the scour bed. At $x / x_{s}>1.33$, a sharp increase of $L_{x}$ can be clearly noted. It shows an average size of $\mathrm{O}\left(40 d_{50}\right)$, and it ranges between a minimum and maximum of $20 d_{50}$ and $54 d_{50}$, respectively. Contrary to the region of high turbulence levels $\left(x / x_{s}<1\right)$, at $x / x_{s}>1.33$, the $L_{x}$-magnitudes rapidly decrease with increasing flow depth, yielding maximum gradient values along the vertical. The integral length scale distribution in the scour hole at equilibrium provides an integrated hydrodynamic picture on the formation and relative macroscopic scales of the turbulent eddies.

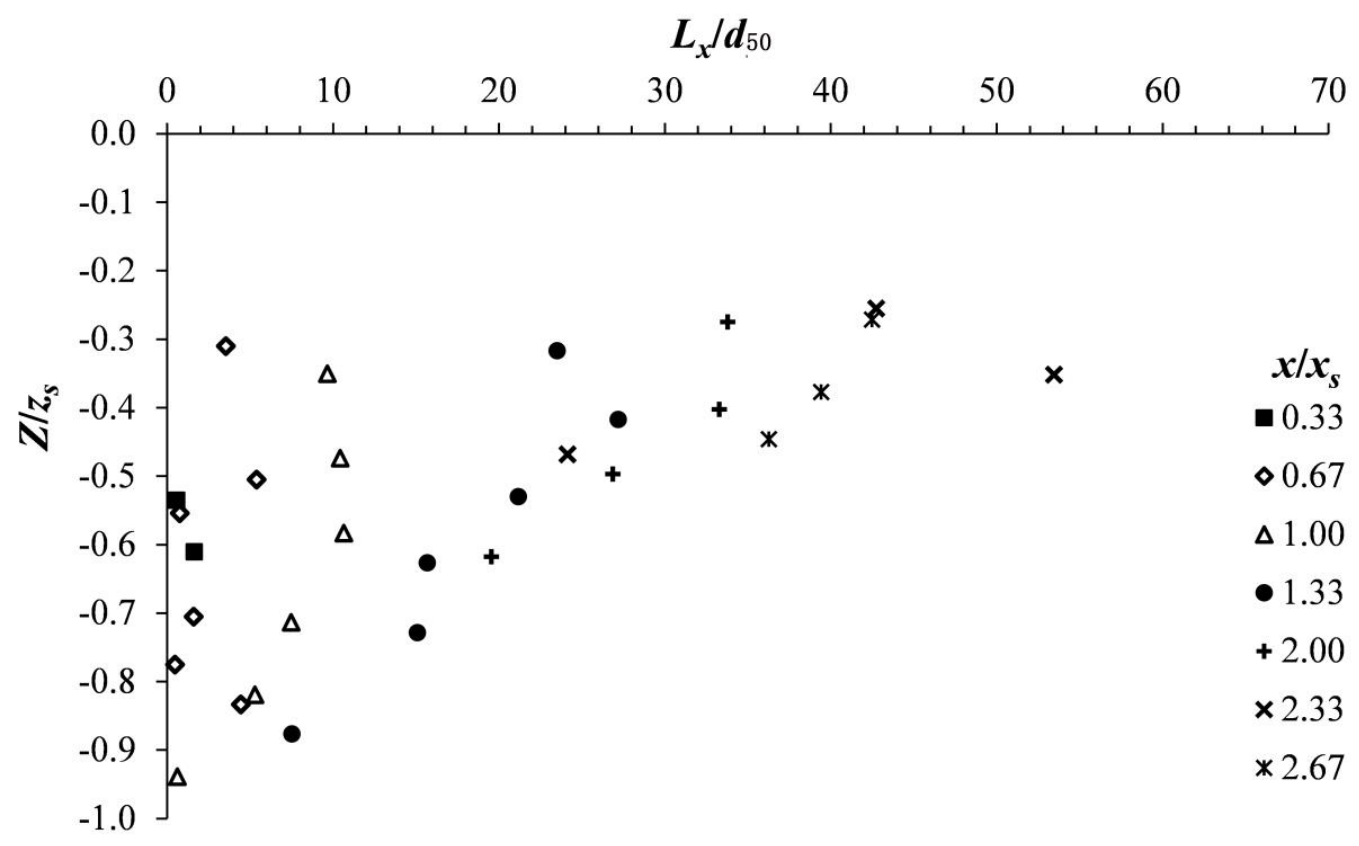

Figure 7. Vertical profiles of normalized turbulent length scales, $L_{x} / d_{50}$, at different downstream positions $x / x_{s}$ at the plane of flow symmetry $(y=0)$.

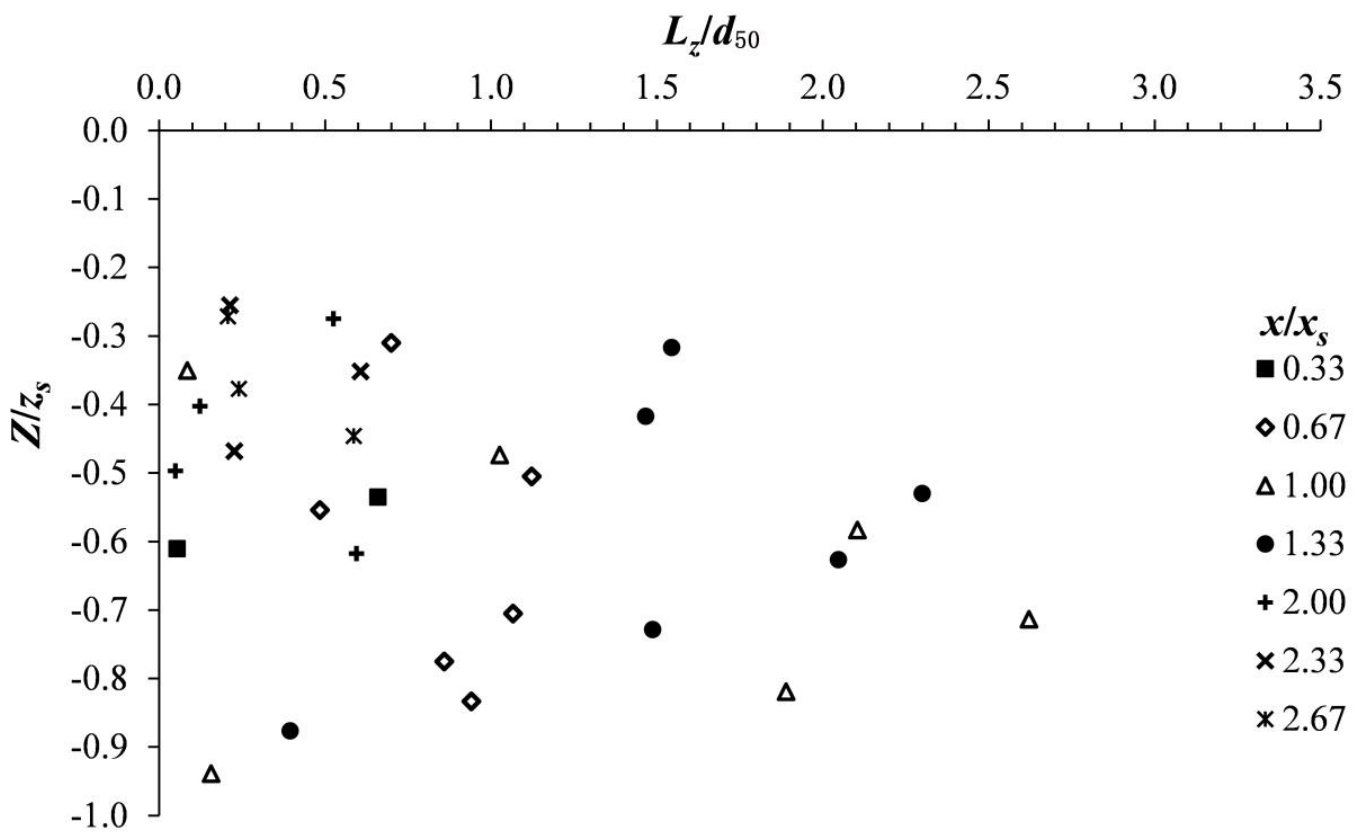

Figure 8. Vertical profiles of normalized turbulent length scales, $L_{z} / d_{50}$, at different downstream positions $x / x_{s}$ at the plane of flow symmetry $(y=0)$. 
Figure 8 illustrates the dimensionless integral length scale $L_{z} / d_{50}$ versus the dimensionless vertical position $Z / z_{S}$ in the scour hole at equilibrium phase. Contrary to what is shown in Figure 7 with $L_{x}$, Figure 8 indicates that the larger values of $L_{z}$ appear at the location of higher turbulence levels. At $x / x_{S}$ $\leq 1.33, L_{z}$ shows both the largest values and the highest gradient along the vertical. It attains maximum values of almost $3 d_{50}$ at $x / x_{s}=1$ and 1.33. These values significantly decrease near the scour bed to an order of $0.1 d_{50}$ to $0.4 d_{50}$. This behavior could play an important role in increasing the vertical lifting force to move the sediment particles before reaching an equilibrium condition. At $x / x_{s}=0.33$ and 1.33, $L_{z}$ slightly decreases to values $\mathrm{O}\left(1 d_{50}\right)$. This distribution of $L_{z}$ at these positions seems reasonable, as it is strongly influenced by the incoming inclined flow-jet in the scour hole, which increases the vertical velocity component. At $x / x_{s}>1.33, L_{z}$ shows very small values, less than $1 d_{50}$. This is explained by the smooth outflow from region 3, as observed in Figure 2, where a streamwise velocity dominance over the vertical component occurs.

The results obtained from the distribution of the integral length scales $L_{x}$ and $L_{z}$ seem to indicate that, in addition to the drag force, the erosion capacity of the flow increases with the increase of the vertical lifting force acting on the sediment particles. The vertical lifting force, essential for moving the sediment particles, is a direct result of an appropriate magnitude of the vertical velocity components.

Figure 9 displays the normalized Kolmogorov's micro-scale $\eta / d_{50}$ versus the normalized vertical coordinate $Z / z_{s}$ at different distances from the bed sills $x / x_{s}$. The main observation from Figure 9 is the expected significant reduction of $\eta$ compared to $L_{x}$ and $L_{z}$, by an average (over all measured points) factor of 340 and 25 , respectively. Through the scour hole, $\eta$ shows values ranging between $0.017 d_{50}$ to $0.044 d_{50}$, an equivalent of 0.04 to $0.15 \mathrm{~mm}$. For the positions $x / x_{s} \leq 1.33$, $\eta$ shows the smallest values, which are almost of constant magnitude along the vertical and are very comparable, indicating a kind of local isotropy of the flow turbulence at these scales. For $x / x_{s}>1.33, \eta$ shows an increase by an almost factor of 1.5 at $x / x_{s}=2$, presenting an average length scale of the order of $0.56 d_{50}$, and then continues to increase monotonically reaching an average value of the order of $0.73 d_{50}$, quite constant at both positions $x / x_{s}=2.33$ and 2.67. Figure 9 indicates that for all profiles, regardless of the positions $x / x_{s}, \eta / d_{50}$ is invariant along the vertical direction. Figure 9 also points out that the size of $\eta$ is influenced by the level of the flow turbulence intensity. In areas of high turbulence, such as at $x / x_{s} \leq 1.33, \eta$ considerably decreases to smaller values. This may be explained by the diffusion of the inlet jet-like flow in the scour hole, which induces the formation of small eddy scales that increase velocity fluctuation.

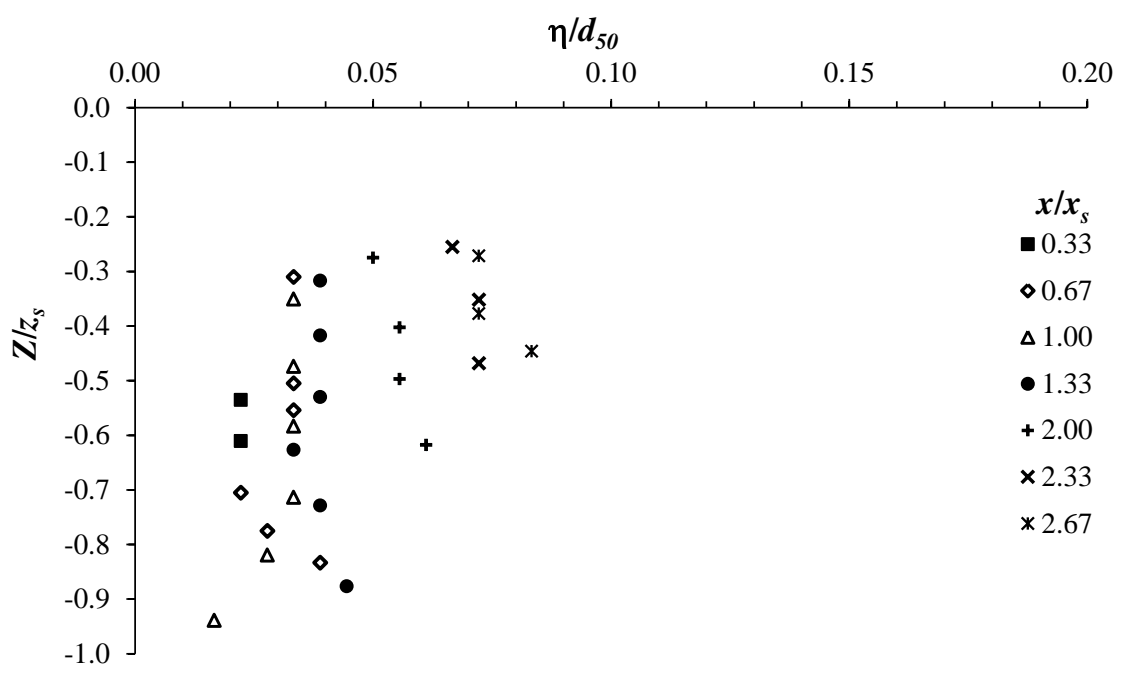

Figure 9. Vertical profiles of normalized Kolmogorov's micro-scale, $\eta / d_{50}$, at different downstream positions $x / x_{s}$ at the plane of flow symmetry $(y=0)$. 


\subsection{Scaling of the Maximum Scour Depth at Equilibrium}

In this section we focus on the scaling of the maximum scour depth at the equilibrium condition, derived from the phenomenological theory of turbulence. At equilibrium, the scour hole between two consecutive bed sills is shown schematically in Figure 10. The scour hole is caused by the effect of a sort of an entering jet flow of both initial thickness and initial velocity comparable, respectively, to the flow depth, $h_{c}$, and its corresponding velocity, $U_{c}$, over the sill. In Figure $10, q$ is the unit water discharge, $l_{s}$ is the equilibrium scour length and $h_{t}$ is the tailwater depth at the position $x_{s}$ of the maximum scour depth at equilibrium, defined as the vertical distance between the initial bed profile and the free-surface flow (at $x_{s}$ the total flow depth is $h_{s}=z_{s}+h_{t}$ ). The effective parameter of the scour hole, illustrated in Figure 10, can be expressed as follows:

$$
h_{s}=z_{s}+h_{t}=f\left(h_{c}, U_{c}, d_{50}, L, S_{0}, g, \rho_{w}, \rho_{s}, v\right)
$$

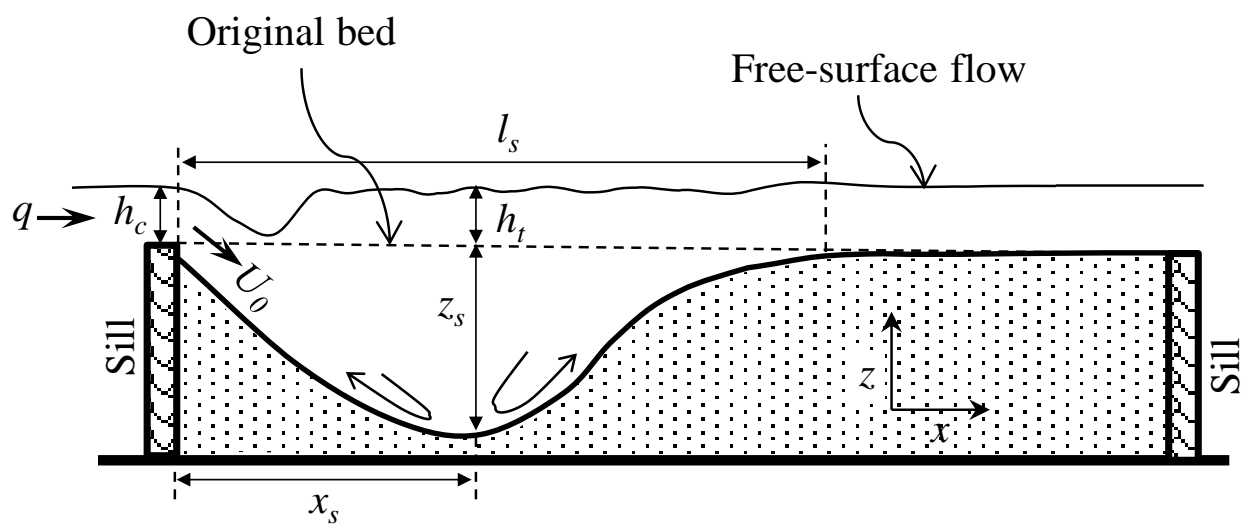

Figure 10. Definitional sketch of scour hole downstream of bed sills, Uo indicates the initial jet velocity.

The application of dimensional analysis to the variables of Equation (3) leads to the following expression:

$$
\frac{h_{s}}{h_{c}}=\frac{z_{s}+h_{t}}{h_{c}}=f\left(\lambda_{c}, \frac{L S_{o}}{h_{c}}, F_{d c}, R e_{c}\right)
$$

For fully turbulent flow, $\operatorname{Re}_{\mathrm{g}}>70$ [31,32], the dependence upon the Reynolds number, $\operatorname{Re}_{\mathcal{c}}$, could be neglected, and therefore Equation (4) can be finally expressed as:

$$
\frac{h_{s}}{h_{c}}=\frac{z_{s}+h_{t}}{h_{c}}=f\left(\lambda_{c}, \frac{L S_{o}}{h_{c}}, F_{d c}\right)
$$

The application of the continuity equation between the section at $x=0$ (over the bed sill) and the section at $x_{s}$, position of maximum scour, yields:

$$
\begin{aligned}
& U_{c} h_{c}=U_{s} h_{s}=U_{s}\left(z_{s}+h_{t}\right) \\
& \frac{U_{c}}{U_{s}}=\frac{h_{s}}{h_{c}}=\frac{\left(z_{s}+h_{t}\right)}{h_{c}}
\end{aligned}
$$

From Equation (2), we can obtain a scaling of the mean velocity $U_{s}$ as:

$$
U_{s} \propto U_{b} \sim \sqrt{\Delta g d_{50}} \lambda^{\frac{(1+\sigma)}{4}} f^{\frac{1}{2}}(D)=\sqrt{\Delta g d_{50}}\left(\frac{d_{50}}{h_{s}}\right)^{\frac{(1+\sigma)}{4}} f^{\frac{1}{2}}(D)
$$


Substituting Equation (7) into Equation (6) produces:

$$
\frac{h_{s}}{h_{c}}=\frac{z_{s}+h_{t}}{h_{c}} \propto F_{d c^{\frac{4}{(3-\sigma)}}}\left(\frac{d_{50}}{h_{c}}\right)^{-\frac{(1+\sigma)}{(3-\sigma)}} f^{-\frac{2}{(3-\sigma)}}(D)=F_{d c^{\frac{4}{(3-\sigma)}}} \lambda_{c}^{-\frac{(1+\sigma)}{(3-\sigma)}} f^{-\frac{2}{(3-\sigma)}}(D)
$$

Since for rough turbulent flow $f(D)$ tends to be a constant function, Equation (8) can be reduced to the following form:

$$
\frac{h_{s}}{h_{c}}=\frac{z_{s}+h_{t}}{h_{c}} \propto F_{d c}^{\frac{4}{(3-\sigma)}} \lambda_{c}^{-\frac{(1+\sigma)}{(3-\sigma)}}
$$

It should be mentioned here that the scaling law of the maximum scour depth at equilibrium, investigated applying the phenomenological theory of turbulence, as shown by Equation (9), is explicitly expressed as a function of only the dimensionless parameters $F_{d c}$ and $\lambda$, also appearing in Equation (5) through dimensional analysis. It should be noted that, contrary to dimensional analysis, the application of the phenomenological theory of turbulence establishes a unique and complete (with defined exponents) relationship between some of the characteristic variables of the scour hole. Since the flow is fully turbulent within the scour hole and the bed sediment is characterized by a relative roughness in the range of $10^{-4}<\lambda_{c}<10^{-1}$ [30], the scaling law is validated for $\sigma=-5 / 3$, in the energy inertial subrange, and thus $F_{d c}{ }^{(4 /(3-\sigma)} \lambda_{c}{ }^{(-(1+\sigma) /(3-\sigma)}=F_{d c}{ }^{(6 / 7)} \lambda_{c}{ }^{(1 / 7)}$. In order to experimentally evaluate the validity of this scaling law, shown in Equation (9), in Figure 11 we plot measured values of $\left(z_{s}+h_{t}\right) / h_{c}$ as a function of $F_{d c}{ }^{(6 / 7)} \lambda_{c}{ }^{(1 / 7)}$. The experimental data used for this scope are those illustrated in Table 1, acquired by Ben Meftah and Mossa [3].

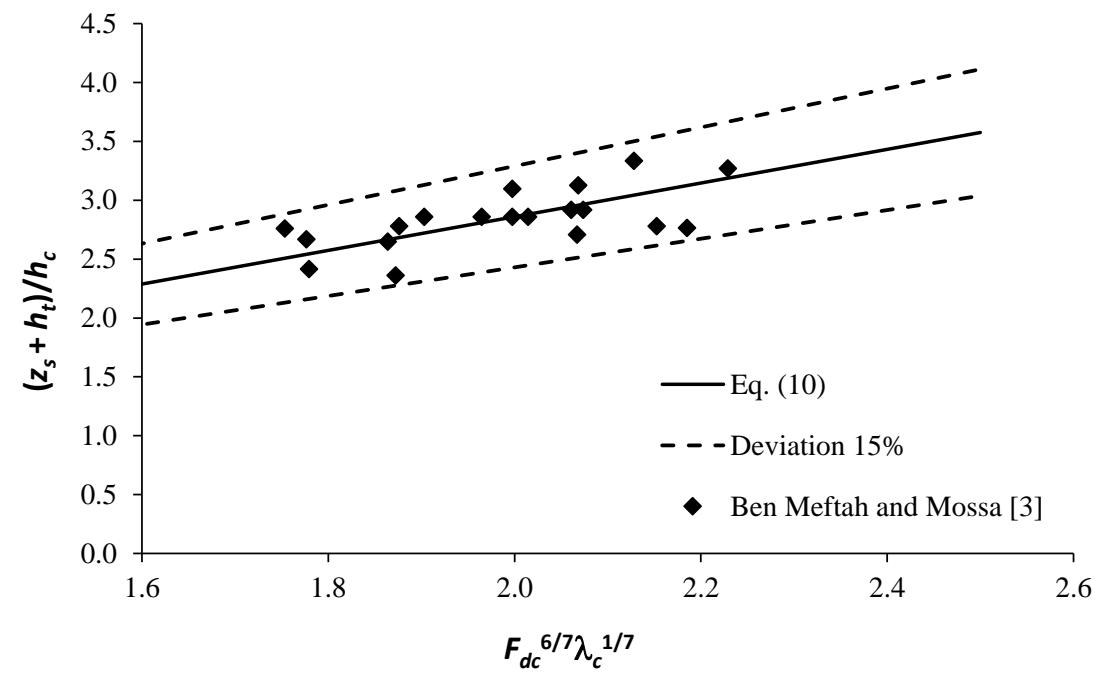

Figure 11. Validation of the scaling law of the maximum scour depth downstream of bed sills obtained by applying the fundamental laws of turbulent energy spectrum with $\sigma=-5 / 3$, and thus $F_{d c}{ }^{(4 /(3-\sigma)} \lambda_{c}{ }^{(-(1+\sigma) /(3-\sigma)}=F_{d c}{ }^{(6 / 7)} \lambda_{c}{ }^{(1 / 7)}$. The data of Ben Meftah and Mossa [3] were obtained downstream of bed sills in alluvial channels and with a bed sediment size of $d_{50}=1.8 \mathrm{~mm}$.

Figure 11 clearly shows that the data of the normalized maximum scour depth $\left(z_{s}+h_{t}\right) / h_{c}$ plotted versus the scaling law $F_{d c}{ }^{(6 / 7)} \lambda_{c}{ }^{(1 / 7)}$ tend to collapse into a single curve. From the interpolation of the data shown in Figure 11 the following expression, predicting the maximum scour depth at equilibrium, is obtained:

$$
\frac{h_{s}}{h_{c}}=\frac{z_{s}+h_{t}}{h_{c}}=1.43 F_{d c^{\frac{6}{7}}} \lambda_{c}^{\frac{1}{7}}
$$

It is worth mentioning that Equation (10) is the regression fitting of data collected downstream of bed sills in alluvial channels. As reported in Ben Meftah and Mossa [3], the distance $L$ between sills varies between 1 and $4 \mathrm{~m}$ and the non-cohesive bed sediment consists of very coarse sand particles of 
mean average size $d_{50}=1.8 \mathrm{~mm}$. Despite the non-presence of the parameter $L S_{0} / h_{c}$ in Equation (10), with respect to Equation (5), which takes into consideration the effects of both the distance and the slope between sills, Equation (10) suitably predicts the maximum scour depth downstream of bed sills at equilibrium condition. This is proved by the low deviation of the data, $\pm 15 \%$, from the best fit line of Equation (10).

To give more validity to this approach, in addition to the data obtained by Ben Meftah and Mossa [3], in Figure 12 we also plot data previously obtained by Bormann and Julien [4]. The scour data of Bormann and Julien [4] were collected downstream of a grade control structure of different face slopes $\left(18^{\circ}, 45^{\circ}\right.$, and $90^{\circ}$ with respect to the horizontal) in a sand-bed channel of $d_{50}$ equal to $0.3 \mathrm{~mm}$ and $0.45 \mathrm{~mm}$. Due to the complexity of the phenomenon and the wide variety of conditions (including different characteristics of the sediment particles, different geometries of the grade control structure, and different entering jet typologies), the data by Bormann and Julien [4], plotted according to the scaling law of Equation (9), show more scattering than those by Ben Meftah and Mossa [3]. As compared to previous studies [4,33], when data were fitted by other scaling laws, the scaling law of Equation (9) predicts with more accuracy the maximum equilibrium scour depth, as shown by the $50 \%$-deviation from the best fit line of Equation (11). In fact, the normalized scour depth $\left(z_{s}+h_{t}\right) / h_{c}$ by Bormann and Julien [4] shows an overall increasing trend as a function of $F_{d c}{ }^{(6 / 7)} \lambda_{c}{ }^{(1 / 7)}$. A linear regression analysis of these data leads to the following expression for predicting the equilibrium scour depth at grade control structures (under Bormann and Julien's [4] conditions):

$$
\frac{h_{s}}{h_{c}}=\frac{z_{s}+h_{t}}{h_{c}}=0.53 F_{d c}{ }^{\frac{6}{7}} \lambda_{c}^{\frac{1}{7}}
$$

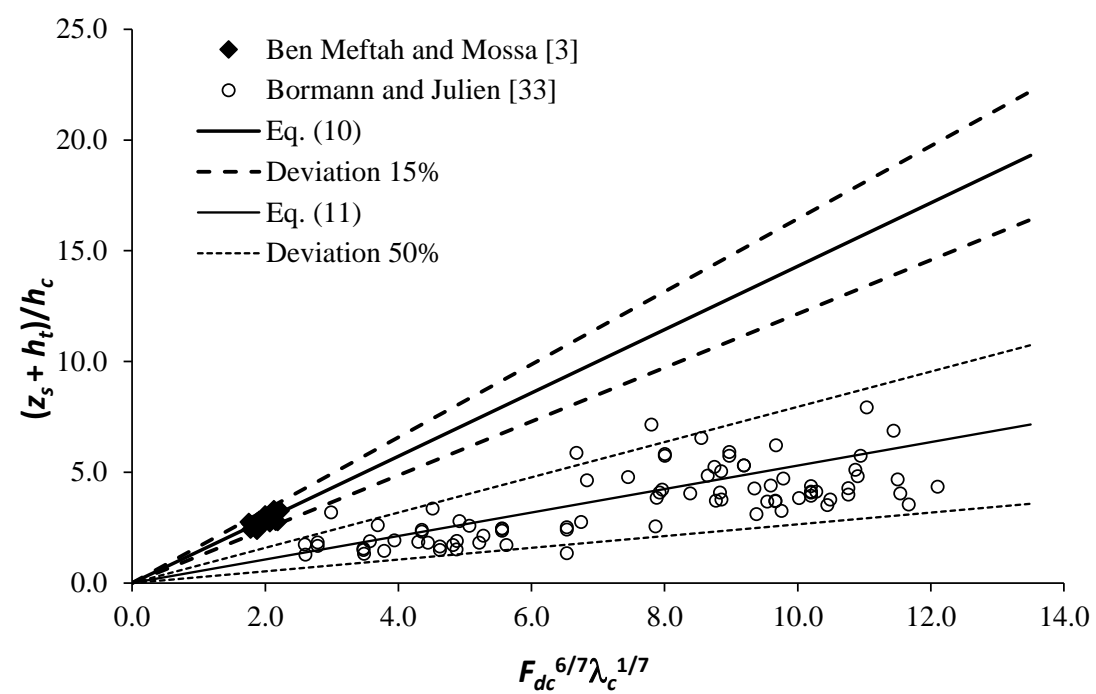

Figure 12. Validation of the scaling law of the maximum scour depth using data obtained by Bormann and Julien [4] downstream of grade control structures of different features and with sediment sizes of $d_{50}$ ranging between 0.30 and $0.45 \mathrm{~mm}, R e_{g}$ ranging between 396 and 2093 and with relative roughness in the range of $10^{-4}<\lambda_{c}<10^{-2}$. The scaling law is validated for $\sigma=-5 / 3$, in the energy inertial subrange.

It is worth noting that the scaling approach introduced by Equation (9) to predict the equilibrium scour depth is only expressed as a function of the densimetric Froude, $F_{d c}$, and the relative roughness, $\lambda_{c}$, with exponents function of $\sigma$. It does not involve all the characteristic parameters affecting the scour features, i.e., the parameter $L S_{0} / h_{c}$ that appears in Equation (5) through dimensional analysis. In any case, its application shows reasonable accuracy in predicting the equilibrium scour depth in different hydraulic structures for sand-bed rivers. The limitation of this approach in the present form, however, is that it does not exhibit a general proportional relationship for all hydraulic structure typologies, 
as shown in Equations (10) and (11) by the coefficients 1.43 and 0.53 . This implies that a further better combination between this scaling approach and other characteristic parameters, obtained through dimensional analysis, can lead to finding a general expression to predict the maximum equilibrium scour depth.

\section{Conclusions}

Considering that an exhaustive prediction of the scour development is fundamental for structural stability, we examined experimentally the local scouring processes downstream of hydraulic grade control structures. This study focuses on the analysis of flow hydrodynamic structures within the scour hole at equilibrium and on the application of the phenomenological theory of turbulence to find a scaling law predicting the equilibrium scour depth.

Specifically, by means of velocity measurements, we observed that at equilibrium conditions the flow in the scour hole is fundamentally characterized by three distinct regions: (i) A first region consists of a free entering jet flow, plunging from the crest of bed sill into the scour hole and strongly eroding the bed sediments; (ii) a second region located near the scour bottom, extending upstream due to vortex formations (eddies) generated by the jet diffusion, allowing to reach the equilibrium condition; and (iii) a third less-turbulent region, localized downstream of the first and the second regions and characterized by an almost unidirectional flow in the $x$-direction.

The detailed analysis of the flow turbulence characteristics in the equilibrium scour hole showed that both the Reynolds shear stresses and turbulence intensities (the streamwise and the vertical ones) exhibit their greatest values in the first region, where the approaching jet has effects, while a sharp reduction of them occurs in the third region. Moreover, these turbulent properties (Reynolds shear stresses and turbulence intensities) show negative vertical gradient going down towards the scour bed. A heterogeneous spatial distribution of these turbulent features is especially evident in the first and second regions, where the jet effect is quite strong. The analysis of the turbulent kinetic energy shows that the region of jet-like flow, region 1, is a location of maximum turbulent energy production. At equilibrium condition, the stability of sediment particles is due to a significant decrease of turbulent energy production at the bed-flow interface.

The distribution of the longitudinal and vertical integral length scales, in the plane of flow symmetry, was also analyzed. The larger values of $L_{x}$ occur almost at the location of lower turbulence levels. On the contrary, $L_{z}$ shows maximum values at the regions of higher turbulence levels. This distribution of $L_{x}$ and $L_{z}$ reflects the role of the flow turbulent eddies in the incipient motion of the sediment particles. The increase of $L_{z}$, related to the increase of the vertical velocity component, enhances the vertical lifting force, giving more possibilities for particles to move.

Finally, the phenomenological theory of turbulence was applied to the scour hole, deducing a new scaling law of the maximum scour depth at equilibrium in non-cohesive bed rivers. Once fixed the spectral exponent of the turbulent energy spectrum, the scaling low becomes a simple function of the densimetric Froude number, $F_{d c}$, and the relative roughness, $\lambda_{c}$. This scaling law was evaluated and validated using laboratory measured scouring data of sand-bed with a relative roughness in the range of $10^{-4}<\lambda_{\mathrm{c}}<10^{-1}$. It showed a quite reasonable accuracy in predicting the equilibrium scour depth in different hydraulic structures.

Author Contributions: M.B.M. performed the experiments, analyzed the data, designed the study and wrote the paper; F.D.S., D.D.P. and M.M. contributed suggestions, discussions and reviewed the manuscript. All authors have read and agreed to the published version of the manuscript.

Funding: This research recevied no external funding.

Acknowledgments: The experiments were carried out at the Hydraulic Laboratory of the Mediterranean Agronomic Institute of Bari (Italy).

Conflicts of Interest: The authors declare that they have no conflicts of interest. 


\section{References}

1. Adduce, C.; Sciortino, G. Scour due to a horizontal turbulent jet: Numerical and experimental investigation. J. Hydraul. Res. 2006, 44, 663-673. [CrossRef]

2. Balachandar, R.; Kells, J.A. Local channel in scour in uniformly graded sediments: The time-scale problem. Can. J. Civ. Eng. 1997, 24, 799-807. [CrossRef]

3. Ben, M.M.; Mossa, M. Scour holes downstream of bed sills in low-gradient channels. J. Hydraul. Res. 2006, 44, 497-509.

4. Bormann, N.E.; Julien, P.Y. Scour downstream of grade-control structures. J. Hydraul. Eng. 1991, 117, $579-594$. [CrossRef]

5. Carstens, M.R. Similarity laws for localized scour. J. Hydraul. Div. 1966, 92, 13-36.

6. D'Agostino, V.; Ferro, V. Scour on alluvial bed downstream of grade-control structures. J. Hydraul. Eng. 2004, 130, 24-37. [CrossRef]

7. Espa, P.; Sibilla, S. Experimental study of the scour regimes downstream of an apron for intermediate tailwater depths. J. Appl. Fluid Mech. 2014, 7, 611-624.

8. Gaudio, R.; Marion, A.; Bovolin, V. Morphological effects of bed sills in degrading rivers. J. Hydrau. Res. 2000, 38, 89-96. [CrossRef]

9. Lenzi, M.A.; Marion, A.; Comiti, F. Local scouring at grade-control structures in alluvial mountain rivers. Water Resour. Res. 2003, 39, 1176. [CrossRef]

10. Mason, P.J.; Arumugam, K. Free jet scour below dams and flip buckets. J. Hydraul. Eng. 1985, 111, $220-235$. [CrossRef]

11. Pagliara, S.; Amidei, M.; Hager, W.H. Hydraulics of 3D plunge pool scour. J. Hydraul. Eng. 2008, 134, 1275-1284. [CrossRef]

12. Papanicolaou, A.N.; Bressan, F.; Fox, J.; Kramer, C.; Kjos, L. Role of structure submergence on scour evolution in gravel bed rivers: Application to slope-crested structures. J. Hydraul. Eng. 2018, 144, 1087-1093. [CrossRef]

13. Wang, L.; Melville, B.W.; Guan, D.; Whittaker, C.N. Local scour at downstream sloped submerged weirs. J. Hydraul. Eng. 2018, 144, 04018044. [CrossRef]

14. Tregnaghi, M.; Marion, A.; Gaudio, R. Affinity and similarity of local scour holes at bed sills. Water Resour. Res. 2007, 43, W11417. [CrossRef]

15. Lu, J.Y.; Hong, J.H.; Chang, K.P.; Lu, T.F. Evolution of scouring process downstream of grade-control structures under steady and unsteady flows. Hydrol. Process. 2013, 27, 2699-2709. [CrossRef]

16. Manes, C.; Brocchini, M. Local scour around structures and the phenomenology of turbulence. J. Fluid Mech. 2015, 779, 309-324. [CrossRef]

17. Gioia, G.; Bombardelli, F.A. Localized turbulent flows on scouring granular beds. Phys. Rev. Lett. 2005, 95, 014501. [CrossRef]

18. Bombardelli, F.A.; Gioia, G. Scouring of granular beds by jet-driven axisymmetric turbulent cauldrons. Phys. Fluids 2006, 18, 088101. [CrossRef]

19. Ali, S.Z.; Dey, S. Impact of phenomenological theory of turbulence on pragmatic approach to fluvial hydraulics. Phys. Fluids. 2018, 30, 045105. [CrossRef]

20. Meftah, M.B.; Mossa, M. Turbulence measurement of vertical dense jets in crossflow. Water 2018, 10, 286. [CrossRef]

21. Meftah, M.B.; Malcangio, D.; De Serio, F.; Mossa, M. Vertical dense jet in flowing current. Environ. Fluid Mech. 2018, 18, 75-96. [CrossRef]

22. Meftah, M.B.; De Serio, F.; Mossa, M.; Pollio, A. Experimental study of recirculating flows generated by lateral shock waves in very large channels. Environ. Fluid Mech. 2008, 8, 215-238. [CrossRef]

23. Meftah, M.B.; Mossa, M. Partially obstructed channel: Contraction ratio effect on the flow hydrodynamic structure and prediction of the transversal mean velocity profile. J. Hydrol. 2016, 542, 87-100. [CrossRef]

24. Meftah, M.B.; Mossa, M. A modified log-law of flow velocity distribution in partly obstructed open channels. Environ. Fluid Mech. 2016, 16, 453-479. [CrossRef]

25. Ben Meftah, M.; De Serio, F.; Mossa, M. Hydrodynamic behavior in the outer shear layer of partly obstructed open channels. Phys. Fluids. 2014, 26, 65102. [CrossRef]

26. Ben Meftah, M.; Mossa, M. Prediction of channel flow characteristics through square arrays of emergent cylinders. Phys. Fluids. 2013, 25, 45102. [CrossRef] 
27. Ben Meftah, M.; Mossa, M.; Pollio, A. Considerations on shock wave/boundary layer interaction in undular hydraulic jumps in horizontal channels with a very high aspect ratio. Eur. J. Mech. B Fluids. 2010, 29, 415-429. [CrossRef]

28. Scurlock, S.M.; Thornton, C.I.; Abt, S.R. Equilibrium scour downstream of three-dimensional grade control structures. J. Hydraul. Eng. 2011, 138, 167-176. [CrossRef]

29. Ghodsian, M.; Mehraein, M.; Ranjbar, H.R. Local scour due to free fall jets in non-uniform sediment. Sci. Iranica. 2012, 19, 1437-1444. [CrossRef]

30. Ali, S.Z.; Dey, S. Origin of the scaling laws of sediment transaport. Proc. R. Soc. A 2017, 473, 20160785. [CrossRef]

31. De Vincenzo, A.; Brancati, F.; Pannone, M. An experimental analysis of bed load transport in gravel-bed braided rivers with high grain Reynolds numbers. Adv. Water Res. 2016, 94, 160-173.

32. Mirauda, D.; De Vincenzo, A.; Pannone, M. Statistical characterization of flow field structure in evolving braided gravel beds. Spat. Stat. 2019, 34, 100268. [CrossRef]

33. Meftah, M.B.; Mossa, M. New approach to predicting local scour downstream of grade-control structure. J. Hydraul. Eng. 2019, 146, 04019058. [CrossRef]

(C) 2020 by the authors. Licensee MDPI, Basel, Switzerland. This article is an open access article distributed under the terms and conditions of the Creative Commons Attribution (CC BY) license (http://creativecommons.org/licenses/by/4.0/). 